\title{
A review of experimental models of focal cerebral ischemia focusing on the middle cerebral artery occlusion model
}

\section{[version 1; peer review: 2 approved]}

\author{
Melissa Trotman-Lucas (iD), Claire L. Gibson (iD) \\ School of Psychology, University of Nottingham, Nottingham, NG7 2UH, UK
}

V1 First published: 26 Mar 2021, 10:242

https://doi.org/10.12688/f1000research.51752.1

Latest published: 11 Jun 2021, 10:242

https://doi.org/10.12688/f1000research.51752.2

\section{Abstract}

Cerebral ischemic stroke is a leading cause of death and disability, but current pharmacological therapies are limited in their utility and effectiveness. In vitro and in vivo models of ischemic stroke have been developed which allow us to further elucidate the pathophysiological mechanisms of injury and investigate potential drug targets. In vitro models permit mechanistic investigation of the biochemical and molecular mechanisms of injury but are reductionist and do not mimic the complexity of clinical stroke. In vivo models of ischemic stroke directly replicate the reduction in blood flow and the resulting impact on nervous tissue. The most frequently used in vivo model of ischemic stroke is the intraluminal suture middle cerebral artery occlusion (iMCAO) model, which has been fundamental in revealing various aspects of stroke pathology. However, the iMCAO model produces lesion volumes with large standard deviations even though rigid surgical and data collection protocols are followed. There is a need to refine the MCAO model to reduce variability in the standard outcome measure of lesion volume. The typical approach to produce vessel occlusion is to induce an obstruction at the origin of the middle cerebral artery and reperfusion is reliant on the Circle of Willis (CoW). However, in rodents the CoW is anatomically highly variable which could account for variations in lesion volume. Thus, we developed a refined approach whereby reliance on the CoW for reperfusion was removed. This approach improved reperfusion to the ischemic hemisphere, reduced variability in lesion volume by $30 \%$, and reduced group sizes required to determine an effective treatment response by almost $40 \%$. This refinement involves a methodological adaptation of the original surgical approach which we have shared with the scientific community via publication of a visualised methods article and providing hands-on training to other experimental stroke researchers.

\section{Keywords}

Stroke, ischemia, focal ischemia, in vivo, refinement

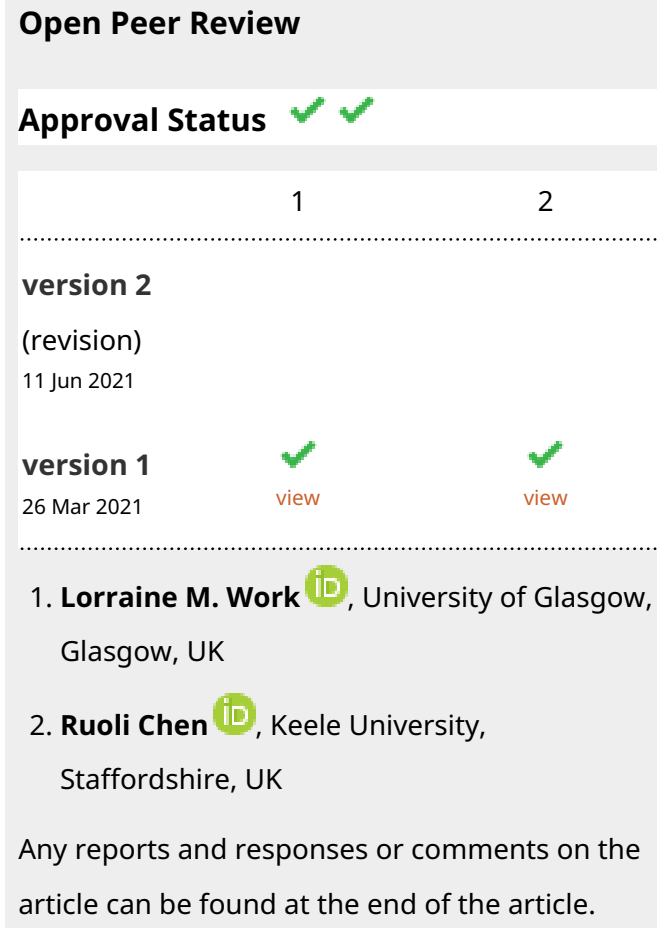

1 2

version 2

(revision)

11 Jun 2021

version 1

26 Mar 2021

1. Lorraine M. Work ID, University of Glasgow, Glasgow, UK

\section{Ruoli Chen (iD), Keele University, \\ Staffordshire, UK}

Any reports and responses or comments on the article can be found at the end of the article. 


\section{NC $3 R^{s}$}

This article is included in the NC3Rs gateway.

Corresponding author: Claire L. Gibson (claire.gibson@nottingham.ac.uk)

Author roles: Trotman-Lucas M: Conceptualization, Writing - Original Draft Preparation, Writing - Review \& Editing; Gibson CL: Conceptualization, Writing - Original Draft Preparation, Writing - Review \& Editing

Competing interests: No competing interests were disclosed.

Grant information: This work was funded by the National Centre for the Replacement, Refinement and Reduction of Animals in Research (NC3Rs; NC/M000117/1 and NC/R000883/1 to C.L.G.).

Copyright: $(2021$ Trotman-Lucas M and Gibson CL. This is an open access article distributed under the terms of the Creative Commons Attribution License, which permits unrestricted use, distribution, and reproduction in any medium, provided the original work is properly cited.

How to cite this article: Trotman-Lucas $\mathrm{M}$ and Gibson CL. A review of experimental models of focal cerebral ischemia focusing on the middle cerebral artery occlusion model [version 1; peer review: 2 approved] F1000Research 2021, 10:242

https://doi.org/10.12688/f1000research.51752.1

First published: 26 Mar 2021, 10:242 https://doi.org/10.12688/f1000research.51752.1 


\section{Ischemic stroke disease}

In the UK alone, over 100,000 strokes occur annually and approximately 1.2 million stroke survivors live with the consequences of a stroke. ${ }^{1}$ Despite innovations in stroke research, treatment and rehabilitation, stroke remains the fourth leading cause of death within the UK. ${ }^{1}$ Stroke is one of the commonest causes of complex disabilities in the UK, ${ }^{2}$ with two thirds of patients leaving hospital with a post-stroke disability, costing the UK society an estimated $£ 26$ billion each year. $^{3}$ A person who suffers a stroke is highly likely to be affected by a variety of debilitating outcomes, including physical (swallowing, pain and sensory changes) and communication difficulties (speech, reading, writing and ability to understand) along with tiredness and fatigue, impacting on the quality of an individual's daily life. ${ }^{4}$ A considerable proportion, $\sim 85 \%$, of strokes that occur are ischemic in nature ${ }^{5}$ occurring when a cerebral vessel becomes blocked, preventing vital blood flow to the supply area of that vessel, ultimately leading to cellular damage and death.

The only current pharmacological treatment available with proven efficacy for ischemic stroke is thrombolysis treatment with recombinant tissue plasminogen activator (rtPA). However, a low number of patients qualify for rtPA treatment, due to strict eligibility criteria, combined with a narrow therapeutic time window of 4.5 hours results in only $\sim 15 \%$ of patients receiving intra-venous rtPA treatment, a low acceptance value further exacerbated by a recanalization success rate of $<50 \%$. $^{6,7}$ In addition to pharmacological treatment, mechanical clot removal via endovascular thrombectomy is increasingly used clinically for the treatment of large vessel occlusions, particularly with patients who respond poorly to rtPA treatment. ${ }^{6,8}$ This technique involves the removal of the clot blockage from directly within the affected vessel, allowing immediate reversal of the clot's impact on blood flow. The prompt restoration of vital blood flow to the ischemic area is the primary clinical goal, with the potential to salvage vital tissue and cellular function, thus reducing the spread of increasing ischemic damage. ${ }^{9}$ This prompt recanalisation of blocked vessels is positively correlated with improved survival rates and improved recovery for ischemic stroke patients. ${ }^{10}$

To allow for the development of useful clinical therapeutics for stroke treatment, the pathophysiology and mechanisms of disease/recovery need to be elucidated. For this to lead to constructive outcomes it is essential to utilise a combined approach of in vitro and in vivo models. Preclinical ischemic stroke models closely mimic the mechanisms of injury and subsequent recovery allowing investigation of potential clinically viable treatments. Although over 1,026 potential neuroprotective therapeutics have been tested preclinically, ${ }^{11}$ breakthroughs have not passed beyond clinical trial often due to detrimental side effects, with current effective treatments concentrating on the chemical or physical unblocking of the occluded vessel. This lack of translation to the clinic of neuroprotective strategies continues, requiring us to re-examine the preclinical models used in research. Revisiting these models, to refine and evolve them to be more clinically representative and consistent between laboratories, aims to improve the robustness of preclinical studies and the reproducibility of data obtained.

\section{Preclinical models of ischemic stroke}

In vitro and ex vivo models of ischemic stroke

Due to the complex nature of ischemic stroke, it is not possible to successfully model using a single in vitro or ex vivo system. However, use of these bench-side systems allows the investigation of biochemical and molecular mechanisms involved during stroke-like ischemic conditions and to examine the resultant cellular damage. These systems can be utilised to determine pathways and cellular triggers involved in both necrotic and apoptotic cell death, ${ }^{12}$ alongside the isolated investigation of cellular cascades that occur as a result of excitotoxicity. ${ }^{13}$ Methods to induce stroke-like ischemic conditions in vitro may include chemical or enzymatic block of cellular metabolism. Metabolic inhibition is induced through application of chemicals such as 2-deoxyglucose, antimycin or sodium azide, ${ }^{14-16}$ which act to interact with the electron transport chain mimicking the energy depletion that occurs during cerebral stroke. Alternatively, a chemicalbased model can use NMDA or glutamate receptor agonists to induce excitotoxic conditions via imitating the significant extracellular increase in glutamate that occurs during ischemia. ${ }^{17,18}$ Chemical or enzymatic bench-side models allow high-throughput testing, with ease of application and rapid responses, the method also allows isolated analysis of specific aspects of the molecular pathways involved. However, both approaches are reductionist in that they only attempt to mimic one aspect of the pathophysiological cascade and don't replicate the more complex interplay of mechanisms. A further disadvantage to the use of chemicals or enzymes to model ischemia is that these compounds may be difficult to wash out and therefore can disrupt the return to pre-insult conditions. The return to pre-insult conditions in vitro is undertaken to mimic the return of nutrients seen in vivo due to the return of blood flow to an area affected by stroke, known as reperfusion.

The most frequently used in vitro method to induce stroke-like ischemic conditions, is to remove all the available oxygen and glucose supply to the cells, known as oxygen-glucose deprivation (OGD). This is most often achieved by perfusing glucose-free media with a nitrogen/carbon dioxide mixture to displace oxygen, with subsequent experiments taking place inside a hypoxia chamber. Reperfusion conditions can be imitated through the reintroduction of glucose alongside 
a return to atmospheric oxygen. Induction of OGD leads to neuronal depolarisation within 10 minutes of onset, ${ }^{19}$ with astrocytes showing immediate progressive depolarisation over the first 30 minutes of OGD. ${ }^{20}$ OGD with reperfusion shows continued neuronal degradation over several hours following a return to 'normal' culture conditions, which combined with large extracellular glutamate increases ${ }^{21}$ are both consistent with in vivo observations. ${ }^{22}$ Experiments undertaken in hypoxic-only conditions are less representative of ischemic stroke but may better represent cerebral hypoxia conditions such as carbon monoxide poisoning. ${ }^{23,24}$ Currently, many in vitro ischemia models mimic global ischemia as they induce an insult to the overall brain slice or culture preparation and therefore do not mimic the clinical situation of a focal insult. Recently, Richard et al. have demonstrated the development of focal OGD in ex vivo cortical brain slices using targeted OGD media stream perfusion, perfusing the tissue surrounding the target area with artificial cerebrospinal fluid (aCSF) solution. They reported rapid neuronal depolarisation within the core OGD targeted area with slower progressive depolarisation in the surrounding aCSF perfused area, such as is seen in the penumbra. ${ }^{25}$ The refinement of an ex vivo slice model of stroke to better represent the clinical presentation of cerebral ischemic events, may allow preclinical bench side investigations to occur in a more representative model.

To gain better relevance from bench side in vitro/ex vivo stroke models, the physiological micro-environment of the cells is critically important to gaining a true understanding of disease process and outcomes. The influence of oxygen, nutrients (including glucose), cell to cell contact and shear forces all need to be considered. With reference to the use of OGD as a key bench side ischemia-inducing model, oxygen levels should be considered when designing and interpreting data from these experiments. Physiological arterial blood oxygen concentrations differ significantly from external atmospheric levels. Maintenance at physiologically relevant oxygen levels has been shown to increase survival, cell proliferation and dopaminergic neuron differentiation in culture. ${ }^{26}$ Whereas, high oxygen levels affect not only basal functioning but also response to challenge, potentially providing resistance to stroke related oxidative stressors. ${ }^{27}$ In addition to high oxygen levels used within in vitro culture systems, glucose is also poorly matched to physiological concentrations. Cell culture glucose concentrations are often up to $8 \mathrm{x}$ higher than those reported within the brain. ${ }^{12,28,29}$ Glucose is used in culture maintenance at concentrations proposed to be present within the brain during severe hyperglycaemia and shown to affect neuronal viability. ${ }^{28}$ A rethink of the use of long-standing outdated culture media maintenance and methods is required to improve physiological relevance.

One step towards improving physiological relevance of in vitro stroke models is the introduction and use of co-culture models which are based on multiple cell types, typically placed in repeated monolayers, allowing substrates and signalling molecules to pass between several cell types. This approach is common for modelling the blood brain barrier and has improved our understanding of neurovascular changes that occur during ischemia. Developments in 3D cell culture have the potential to improve the physiological relevance of bench side ischemia models even further. Cells cultured in 3D, on either scaffolds or a scaffold-free system, show natural cell shapes, prevalent cell to cell junctions, well differentiated cell types and a greater response to mechanical stimuli, overall improving physiological relevance compared to $2 \mathrm{D}$ culture models. ${ }^{12,30}$ Cells show lower mortality rates, resistance to nutrient deprivation and drug insults, this is alongside the presence of a gradient based availability of culture media nutrients more like that of a physiological state. Popularity and interest in the use of 3D cultures for in vitro modelling is increasing and they offer an additional way to investigate potential neuroprotective treatments prior to the need for in vivo approaches, reducing ethical impact. In addition to the use of bench side models of multiple cell types to increase physiological relevance, the use of microfluidic devices is also being explored to improve the relevance and applicability of bench side disease models, often termed organ-on-a-chip models. ${ }^{31}$ Microfluidic devices, since the advent of lithography in $2001,{ }^{32}$ use a micro-engineered culture platform that can be utilised to mimic blood flow in health and disease models, alongside allowing the isolated investigation of upstream and downstream signalling within and between cells, due to microchannels that allow axonal growth along them. Since the early 2000s there have been multiple developments in the field of biomicrofluidics to try to overcome some of the limiting factors of this type of cell culture, as this is still constrained to the typical 2D rigid culture techniques discussed earlier. Improvements towards a brain-on-a-chip model are still required, but the use of microfluidics devices for axon-specific responses, cell-cell interaction and high-throughput screening are of great interest to the preclinical stroke research community, and with advancements in the field may prove to be another key step in the drug translation process that will help improve the positive potential of tested neuroprotective therapeutics within the clinic. Although in vitro research provides a platform to determine and understand cell-specific responses to stroke-like conditions the complexities of clinical stroke often require these methods to be combined with in vivo approaches.

\section{In vivo models of ischemic stroke}

The significant lack of neuroprotective therapeutics in the clinic has led to extensive work aimed at improving the reproducibility of preclinical stroke models and to ensure they reflect as closely as possible the clinical disease. ${ }^{33-36}$ To date, multiple preclinical stroke models have been developed to reproduce both global and focal ischemic stroke. Whereas global ischemia models more closely mimics the situation of cardiac arrest, focal ischemia models represent the 
typical clinical presentation of ischemic stroke. Various models are available for use in a variety of animal species, however the use of rodents, specifically rats and mice, is the most common. This is likely to be due to low acquisition and husbandry costs associated with these species, combined with simple effective monitoring methods and ease of tissue processing. ${ }^{24}$ To try and address the gap in clinical translation for stroke treatments the Stroke Therapy Academic Industry Roundtable (STAIR) published a number of recommendations including the need for potential therapeutics to be assessed across a number of species, initially rodents followed by studies using gyrencephalic species. ${ }^{33,37}$ The use of higher-order species is necessary to overcome the evolutionary differences between rodents and primates such as the corticospinal tract descending from the motor cortex. ${ }^{38}$ Larger species may also be suitable for investigations utilising endovascular techniques, such as clot retrieval and stenting, techniques used more frequently in the clinic. However, due to cost, availability and ethical considerations with larger higher-order species, rodents still play a key role in research to ensure experimental power in addition to testing the safety and efficacy of potential neuroprotective treatments.

The most frequently used in vivo model of focal ischemia is intraluminal suture middle cerebral artery occlusion (iMCAO), ${ }^{39}$ which has enhanced our knowledge of the pathophysiology of cerebral ischemia including penumbra development and functioning, blood brain barrier injury, cell death pathways and inflammatory processes related to cerebral ischemia. Developed initially for use in the rat, ${ }^{40}$ in which infarction success rates are $88-100 \%,{ }^{41}$ the method was later modified by Longa et al. $^{42}$ and subsequently adapted for use in mice ${ }^{43}$ where the model is increasingly being used particularly due to the availability of transgenic mouse strains. Induction of iMCAO is achieved by the insertion of a flexible monofilament into either the common carotid artery $(\mathrm{CCA})^{40}$ or external carotid artery (ECA). ${ }^{42}$ Access into the CCA requires the vessel to be ligated for incision. ${ }^{40}$ Similarly, for filament access, the ECA is typically transected in the modified iMCAO method. ${ }^{42}$ Once in the vessel lumen, the filament is advanced into the internal carotid artery (ICA) and to the bifurcation of the middle cerebral artery (MCA). Once in situ, at the origin of the MCA, the filament head impedes blood flow into the MCA territory and is left in situ for the duration of ischemia. The utility of this model allows for accurate control of occlusion duration, allowing for either permanent ischemia where the filament remains in place, or transient ischemia where the filament is removed to allow reperfusion of blood flow to the MCA territory. Utilising the iMCAO model, post-stroke effects can be examined months following the initial insult. Vessel access is obtained without craniectomy and therefore avoids cranial damage associated with craniectomy which could impact on intracranial pressure changes and post-stroke outcomes such as reduced lesion volume. ${ }^{44,45}$ Use of iMCAO results in large infarct volumes encompassing both the striatum and cortex, ${ }^{46,47}$ however, longer durations of iMCAO can lead to hypothalamic damage which occurs rarely in humans and can lead to hyperthermic responses in rats and poor temperature control in mice. ${ }^{48,49}$ Following iMCAO, rodents can experience a range of side-effects that negatively impact the welfare of animals, including but not limited to, significant weight loss, abnormal or reduced motility, difficulty eating/drinking and mortality. These outcomes can be moderated through enhanced pre and post-surgery care; detailed recommendations to support this have been highlighted by the IMPROVE guidelines. ${ }^{50}$

The filament selection for use within iMCAO also plays a key role within the model, as unsuitable filament selection can lead to inadequate occlusion and filament-induced secondary subarachnoid haemorrhage due to arterial rupture. ${ }^{51}$ This has led to an increase in the use of standardised silicone-coated filaments to attempt to improve reproducibility and the use of laser doppler flowmetry to confirm correct filament placement and monitor occlusion duration. ${ }^{52}$ Although the iMCAO model is not appropriate to study the effect of thrombolysis treatment in conjunction with tested therapies it does recapitulate occlusion of the MCA in the clinic, which is the most common location of thromboembolic stroke in humans. ${ }^{53}$ However, placement of the intraluminal filament into the origin of the MCA is an all or nothing approach, which does not reflect the clinic where human stroke is frequently not caused by a complete occlusion, additionally the model does not replicate the event of partial spontaneous reperfusion that can occur in patients within 48 hours of stroke onset. ${ }^{54,55}$ Furthermore, the model does not profile the slow clot disruption that occurs following rtPA administration, instead showing surge reperfusion upon filament removal. ${ }^{56}$ More recently however, the model has become increasingly relevant due to the advent of interventional mechanical thrombectomy in the clinic. In 2015, five randomised controlled clinical trials reported beneficial effects of endovascular intervention therapy in treating patients with large vessel occlusions, with or without rtPA treatment. ${ }^{57}$ This beneficial effect was correlated with the abrupt recanalisation of the vessel and rapid reperfusion of the ischemic zone, corresponding to the mechanisms of the iMCAO model. The positive outcome of endovascular thrombectomy, as reported in the clinical trials, suggests this mechanical treatment will become the primary therapy for large vessel occlusion in the clinic; ${ }^{56}$ renewing relevance of the established iMCAO model as a model of endovascular thrombectomy.

In addition to iMCAO, focal ischemia can also be induced in vivo by direct occlusion of the vessel of interest, using a cranial window to either clamp, ligate or cauterise the vessel in situ. The most used cranial entry focal ischemia method was developed in 1981 by Tamura et al., using distal MCA occlusion, similar to the occlusion location obtained using iMCAO, inducing combined cortical and striatal lesions. ${ }^{58}$ Like the iMCAO method, craniotomy models can be used to 
induce either permanent or transient focal ischemia - although relying heavily on the experimenter's ability to reduce potential localised cerebral damage for both scenarios. Similarly, the return to perfusion following transient ischemia using this method results in a sudden prompt mechanical perfusion, again unlike the presentation of reperfusion in the clinic. Furthermore, access to the vessel of interest through the skull has been shown to induce cortical spreading depressions and inflammatory responses. ${ }^{59}$

Additional stroke models are available that utilise specialised mechanisms to induce ischemia, typically in rodents, including thromboembolic, endothelin-induced and photochemical models. Embolic models can be broadly categorised into thromboembolic and non-clot embolic models; the former utilising the induction of localised clots or the insertion of spontaneous/thrombin-induced clots and the latter utilising non-clot methods such as micro/macrospheres to occlude vessels. ${ }^{52,60,61}$ Since most human strokes are caused by thromboembolism, thromboembolic stroke models may more closely represent the clinical disease pathology. However, there is a lack of a single standardized embolic stroke model leading to multiple occlusion induction methods, a further method that has shown increasing use is the localised injection of thrombin directly into a craniotomy exposed MCA bifurcation. ${ }^{62}$ A significant advantage of this thromboembolic technique is the opportunity to test thrombolysis treatments alone or in combination with neuroprotective agents. ${ }^{63,64}$ Additionally, the use of rtPA to lyse the clot in thromboembolic models results in a reperfusion profile that is closer to the reperfusion profiles of rtPA treated patients, contrasting the sharp reperfusion profile following filament removal using iMCAO, increasing the relevance of clot emboli models. ${ }^{56,65}$ However, infarct location and volume can be highly variable using thromboembolic stroke models along with low seven-day survival rates, ${ }^{66}$ which impacts the reproducibility of thromboembolic stroke models and their utility for longitudinal studies. In addition to the difficulties experienced in controlling lesion location, the duration of the ischemic insult is difficult to control in these models with some animals showing spontaneous recanalisation, ${ }^{62,67,68}$ a further disadvantage to the model is the potential for spontaneous clot formation following embolism disruption. ${ }^{69}$ The severity of this preclinical stroke model also has a high mortality rate of $>30 \%$, typically within the first 24 hours preventing longitudinal study. ${ }^{50,70}$ Non-clot embolic methods can include the injection of silicone or collagen into the ICA of rodents ${ }^{71,72}$ or, for example, the injection of micro/macrospheres resulting in microembolisations causing multifocal and heterogenous lesions. ${ }^{73,74}$ Administration of micro/microspheres results in an immediate reduction in cerebral blood flow (CBF) that becomes progressively stronger over the first 3-12 hours following sphere injection, this in turn leads to a slow infarct development, suggesting a longer therapeutic time window than other stroke models for instance iMCAO. ${ }^{74}$

Endothelin models of ischemia employ the peptide Endothelin-1, a long-lasting potent vasoconstrictor, to induce vessel occlusions. $^{75,76}$ The peptide is typically applied using stereotaxic injection methods ${ }^{77,78}$ or craniotomy ${ }^{79,80}$ applied directly onto an exposed cerebral vessel causing a constriction of the vessel reducing CBF to the vessel territory for up to 22 hours post-injection ${ }^{81}$ followed by gradual reperfusion. The severity and duration of an insult can be adjusted according to the concentration of the peptide at application. The sustained reduction in CBF and subsequent gradual reperfusion profile, alongside gradual lesion development resembles the evolution of clinical stroke. The topical application method of the peptide is a source of variability in this model, due to the difficulty in ensuring consistent diffusion. To reduce this variability intracortical injection of the peptide to sensorimotor areas has been developed. ${ }^{82,83}$ With this injection based method, care must be taken to avoid the compound entering the ventricles to avoid significant negative welfare outcomes such as barrel rolling or seizures. ${ }^{69}$ Another targeted approach of MCA occlusion induction is the photothrombotic stroke model, which induces localised permanent infarcts of the cortex by introducing a photosensitive dye (e.g. Rose Bengal) into the cardiovascular system and illuminating this through the skull using a specific wavelength of light. Targeting small vessels, this illumination activates the photosensitive dye resulting in endothelial damage due to oxygen species formation, causing platelet activation and aggregation. ${ }^{84,85}$ These together result in the formation of an occlusion and consequently rapid ischemia to the vessel territory, leading to the development of cortical lesion. ${ }^{86}$ This method produces reproducible and localised cortical lesions, with minimal variation in lesion volume, ${ }^{86}$ the small cortical lesions and low mortality associated with the model lend well to longitudinal study however, a lack of penumbral tissue within the lesion reduces the translational impact of the model, as the penumbra is the target tissue of interest for neuroprotective strategies. Photothrombotic induction requires the use of light sources, these can act as a heat source. The illumination can have a heating effect on the skull and subsequently the brain, therefore it is important that care over temperature must be taken and where possible cold light sources used, with exposure and distance from the skull/brain considered. ${ }^{50,82}$ Furthermore, due to the systemic nature of the dye the model is unsuitable for preclinical drug studies.

\section{Refining the in vivo model of iMCAO}

The lack of lab to clinic translation of neuroprotective therapies is an ongoing issue and understanding the reasons for this is key to improving the future clinical potential of preclinical stroke research. Many in the field have deliberated the difference in outcomes between preclinical data and the clinical trial outcomes of the many tested neuroprotective 
agents. ${ }^{35,87-90}$ Reasons conferred for the disparity include; variations in treatment implementation timepoints, queries about dose effectiveness between species, outcome measure disparities between preclinical (typically lesion volume) and clinical (mainly death rate and disability) also, whether in vivo models effectively model drug efficacy. ${ }^{89,90}$ Moreover, systematic meta-analyses suggest the introduction of bias into data as a result of poor study design and subsequent study implementation. ${ }^{90-92}$ With sources of bias coming from both internal (e.g. selection or, performance or attrition bias, small sample sizes and low overall power) and external (e.g. publication bias and the use of exclusion criteria such as co-morbidities, age and sex) factors, acting to weaken the strength of studies.

The most commonly used in vivo model of ischemic stroke, iMCAO, has been shown to produce lesion volumes with large standard deviations even though rigid surgical and data collection protocols are followed, ${ }^{88,93,94}$ with $40 \%$ standard deviation accepted as reproducible infarct outcomes. ${ }^{95}$ The iMCAO model relies heavily on collateral flow through the Circle of Willis (CoW), a network of vessels connecting vertebral and carotid circulation, particularly at reperfusion due to ipsilateral CCA ligation. Reliance on the CoW may afford some of the variability in lesion volume reported following iMCAO, due to anatomical variations in its structure, particularly within C57BL/6 (B6) mice commonly used in preclinical stroke studies. CoW variation has been shown to occur in B6 mice, with $90 \%$ showing one or both posterior communicating arteries (PcomA) missing. ${ }^{47}$ Kitagawa et al., reported that the patency of the PcomA is a significant determinant of ischemic damage area following iMCAO. ${ }^{96}$ Furthermore, additional models of cerebral ischemia such as the bilateral common carotid artery occlusion model also report variations attributed to PcomA patencies, in both lesion volume and CBF during ischemic events, when compared across mouse strains. ${ }^{97-99}$ Variation in experimental design and husbandry techniques may also impact the potential translational ability of iMCAO studies. Recommendations provided by the IMPROVE guidelines ${ }^{50}$ on experimental design, husbandry, enrichment, analgesia and post-operative care may go some way to improving standardisation and welfare across iMCAO studies, reducing variability not only within but between studies. This may contribute towards improving the reproducibility of preclinical stroke research, allowing the focus to be on the experimental question and assessing this across research groups with a collaborative approach to research. The IMPROVE guidelines also stress the need for comprehensive reporting of confounding factors in published research, to allow correct interpretation of presented data, improving the reliability and adding value to the information provided, not only improving welfare but also consistency across the stroke research field.

We have previously reported an alternative surgical approach to iMCAO that improves reperfusion to the ischemic hemisphere, reduces lesion volume variability and subsequently reduces group sizes estimated, using power calculation, to determine an effective treatment response in terms of lesion volume. ${ }^{100,101}$ Typically, in iMCAO, entry to the cerebrovascular system is obtained via an incision into the CCA or transection of the ECA. However ECA transection, in rats, has been shown to induce ischemic lesions within the muscles controlling mastication and swallowing, ${ }^{102}$ resulting in changes to drinking behaviour and weight-loss post-MCAO. ${ }^{103}$ Preclinical stroke models, including iMCAO, that utilise ECA transection do so to minimise interruption to circulatory flow, in an attempt to maintain anatomic integrity to improve post-stroke reperfusion. ${ }^{104}$ We reported that avoidance of ECA ligation, alongside the introduction of analgesia, appeared to reduce weight loss, without impacting lesion volume when using the modified iMCAO method. ${ }^{101}$ Although limitations in experimental design did not allow the elucidation of the direct effects of analgesia versus ECA ligation avoidance, systematic administration of an analgesia regime across all experimental groups prevented this becoming a confounding variable. Analgesia use should be utilised in preclinical stroke research as a means of good practice, particularly as many preclinical stroke models involve surgical interventions, with the type of analgesia carefully selected in relation to any potential interference with a study's scientific outputs. The IMPROVE guidelines provide a comprehensive discussion on the use of analgesics within preclinical stroke research, providing recommendations to promote analgesia use within the field. ${ }^{50}$

The alternative iMCAO method we established improves mouse well-being and removes reliance on the CoW for collateral flow during reperfusion, importantly reducing lesion volume variability. ${ }^{100,101,105}$ As lesion volume is often the primary outcome measure for neuroprotective in vivo stroke research, large variations within this data can result in low statistical power if sample sizes are not accordingly adjusted to account for this variability. ${ }^{93}$ Typically, preclinical stroke studies have low statistical power, a statement supported recently by a meta-analysis revealing that on average, studies show $59 \%$ power to detect a $30 \%$ inter-group difference. ${ }^{93}$ The low power of experimental stroke studies, in simple terms, could be improved by increasing group sizes, however, this is contrary to the research community's drive to implement the 3Rs principles, where it is important to ensure studies are correctly powered. ${ }^{106,107}$ The need to use appropriate animal numbers in experimental research, in line with ethical requirements and the 3 Rs principles is leading researchers to re-address the models used and experimental designs undertaken, in addition to the need to overcome the translation roadblock in neuroprotective stroke research. The iMCAO model refinement is one step within the preclinical stroke community towards reducing animal numbers. This is due to reduced variability in outcome data, improving statistical power, and leading to reduced animal numbers required per experimental group to determine treatment effect. We 
demonstrated that undergoing CCA repair following iMCAO increased perfusion to the ipsilateral hemisphere compared to a typical CCA ligation iMCAO method ${ }^{100}$ and that use of the CCA repair model could require group sizes $39 \%$ smaller than with use of the traditional CCA ligation technique, to attain $80 \%$ power with a significance level of 0.05 and an anticipated $30 \%$ difference in lesion volume between groups. ${ }^{101}$ For a typical year, in this instance 2019, a Pubmed search using the search term '((MICE) OR (mouse)) and (MCAO))' determined there were 210 original research articles reporting data from mice undergoing iMCAO. Based on data we reported previously, ${ }^{101}$ a group size of 58 animals per group (control and experimental condition) per article can be assumed - this group size would result in 24,360 animals per year, but of course that does not include excluded animals alongside those animal experiments that were either not included in published studies or were never completed and analysed for publication. A 39\% reduction in group size, as reported following use of the CCA repair iMCAO method, ${ }^{101}$ would reduce the number of animals required across all those studies published in 2019 by 9500.

\section{Scientific applications of refinements}

The iMCAO CCA repair method we have highlighted here could have impact on other vascular surgical models within the preclinical stroke research field and potentially beyond. For example, embolic stroke models that deposit a clot into the cerebral vascular system via a carotid artery could be adapted to incorporate the demonstrated CCA repair method. Particularly, by accessing the vessel lumen through the CCA rather than the ECA, alongside the vessel sealing aspect of the refinement allowing bilateral CCA perfusion to the affected ischemic area. The refined iMCAO model using the CCA repair technique may also be of use in additional in vivo research applications, for instance therapeutic drug delivery in experimental models or intra-arterial delivery (IA) of stem cells. Currently there have been over 50 IA cell delivery studies within the stroke field ${ }^{108}$ with potential IA applications in other research fields. Argibay et al. 2017 , reported that maintaining flow through the CCA resulted in uniform cerebral cell distribution following IA cell delivery, with engraftment of labelled mesenchymal stem cells (MSC) visualised using T2-weighted magnetic resonance imaging. ${ }^{109}$ The group utilised Longa's ${ }^{42}$ transient iMCAO method in rats, with both filament insertion and MSC injection via a transected ECA, with the CCA temporarily tied for the duration of iMCAO. ${ }^{109}$ CCA repair, reported previously to be successful in rats, ${ }^{110,111}$ alongside our recent method development in mice, ${ }^{101,105}$ would negate the requirement to transect the ECA, therefore, removing the negative welfare outcomes reported following ECA transection. ${ }^{102,103,110}$ Although many IA stem cell delivery experimental models utilise rats, there are examples of these studies conducted in mice. Ge et al. 2014, utilised transgenic mice expressing green fluorescent protein to assess the impact of MSC size on neuronal health in naive animals undergoing IA MSC infusion, during which multiple arteries were transected and coagulated to enable catheter placement. ${ }^{112}$ The delicate nature and small size of mouse arteries, compared to the typically more robust nature of rat arteries, increases the difficulty and applicability of IA procedures, potentially discouraging the development of improved methods utilising mice, even though the use of mice over rats opens-up the possibility of transgenic line use, and the targeted downstream investigations the use of transgenic animals allows. Use of the CCA repair technique provides an attractive solution to the problem of vessel sealing following arterial incision in mice, removing reliance on the CoW for collateral flow across the brain. Studies using IA delivery of MSC alongside stroke induction, typically induce iMCAO via the Longa et $a l .{ }^{42}$ method of ECA transection for filament introduction. This is due to the need to maintain CCA flow for microneedle injection of cells, as evidence suggests the injection of MSCs into a no flow vessel results in micro stroke lesions due to the preserved flow within the injection vessel. It is therefore possible that the repair technique could have an impact in this field, allowing the induction of stroke conditions but allowing CCA perfusion post iMCAO induction to allow IA microneedle injection. For catheter-based IA models, the sealing of the CCA vessel rather than the ligation of this vessel may be able to be undertaken with adaption of the CCA repair technique.

\section{Dissemination and uptake of the refined in vivo model of iMCAO}

Our overall aim in producing a refined model of iMCAO was to achieve 3Rs impact within the field of experimental stroke. The importance of this work is in demonstrating that reduced variability in animal stroke studies has the potential to increase animal wellbeing, reduce the number of animals used and potentially increase the efficacy of animal studies in detecting treatment effects. Within a scientific field, results are typically disseminated through scientific publications and any methodological adaptations, if successful, tend to be taken up relatively slowly by the community. Researchers prefer to use 'established techniques' and are resistant to changing methods they have successfully applied for many years. However, there is a real commitment within the stroke community to improve the reliability and reproducibility of animal stroke models so that they may better inform the design and outcomes of clinical trials, evidenced by recent steering papers such as the IMPROVE guidelines. ${ }^{113}$ We have engaged proactively with the stroke community to deliver hands-on training to numerous labs in the UK, Germany and USA involving over 20 researchers. To extend the reach into the community we published a visualised method of our refined approach ${ }^{105}$ which has been viewed over 8000 times since publication in early 2019 and over 2000 times in the last six months. Subsequent work published by ourselves and others brings attention to this refined approach and we continue to offer it as our standard training model to incoming members 
of our group and in other research groups who contact us for training advice. ${ }^{50}$ We feel that by engaging with some of the key preclinical stroke labs worldwide we will speed up the adoption of this refined technique.

\section{Conclusion}

To further understanding of stroke pathophysiology and to develop novel clinical therapeutics experimental models of ischemic stroke are beneficial. Such models, based on both in vitro and in vivo approaches, have greatly enhanced our understanding of stroke physiology and pathology. However, there is still a lack of successful clinical therapies being translated from preclinical bench work to clinical use. As various types of in vitro and in vivo models have been developed selection of the most appropriate model to test the therapeutic is key. However, it is also necessary to constantly strive to improve the validity of the models being used in terms of their relevance to the clinical situation and to improve animal wellbeing. Here, we focus on the middle cerebral artery occlusion model which is the most commonly used in vivo stroke model. The refined surgical approach described here reduces the variability, in lesion volume, associated with this model and improves the welfare of experimental animals.

\section{Data availability}

No data are associated with this article.

\section{References}

1. Association, S:State of the nation: Stroke statistics. 2018; Stroke Association: London

2. Adamson J, Beswick $A$, Ebrahim $S$ : Is stroke the most common cause of disability?. J Stroke Cerebrovasc Dis. 2004; 13(4): 171-7. PubMed Abstract | Publisher Full Text

3. Patel A, et al.: Current, future and avoidable costs of stroke in the UK. Executive summary Part 2: Societal costs of stroke in the next 20 years and potential returns from increased spending on research. 2017; Stroke Association: London.

4. Association, S: Effects of Stroke. 2020 [cited 2020 19/08/2020]; Reference Source

5. Party ISW: National clinical guideline for stroke. 2016; Royal College of Physicians.

6. Bhaskar S, et al.: Reperfusion therapy in acute ischemic stroke: dawn of a new era?. BMC Neurol. 2018; 18(1): 8 PubMed Abstract | Publisher Full Text | Free Full Text

7. Grech $\mathrm{R}$, et al.: Functional outcomes and recanalization rates of stent retrievers in acute ischaemic stroke: A systematic review and meta-analysis. Neuroradiol J. 2015; 28(2): 152-71. PubMed Abstract | Publisher Full Text | Free Full Text

8. Liaw N, Liebeskind D: Emerging therapies in acute ischemic stroke. F1000Res. 2020; 9.

PubMed Abstract | Publisher Full Text | Free Full Text

9. Balami JS, et al:: The exact science of stroke thrombolysis and the quiet art of patient selection. Brain. 2013; 136(Pt 12): 3528-53. PubMed Abstract | Publisher Full Text

10. Rha JH, Saver JL: The impact of recanalization on ischemic stroke outcome: a meta-analysis. Stroke. 2007; 38(3): 967-73. PubMed Abstract | Publisher Full Text

11. O'Collins VE, et al.: 1,026 experimental treatments in acute stroke. Ann Neurol. 2006; 59(3): 467-77. PubMed Abstract | Publisher Full Text

12. Holloway PM, Gavins FN: Modeling Ischemic Stroke In Vitro: Status Quo and Future Perspectives. Stroke. 2016; 47(2): 561-9. PubMed Abstract | Publisher Full Text | Free Full Text

13. Choi DW: NMDA receptors and AMPA/kainate receptors mediate parallel injury in cerebral cortical cultures subjected to oxygenglucose deprivation. Prog Brain Res. 1993; 96: 137-43. PubMed Abstract | Publisher Full Text

14. Carpanese $\mathrm{E}$, et al.: Antagonism of ionotropic glutamate receptors attenuates chemical ischemia-induced injury in rat primary cultured myenteric ganglia. PLoS One. 2014; 9(11): e113613.

PubMed Abstract | Publisher Full Text | Free Full Text

15. Marino $S$, et al.: Mechanisms of sodium azide-induced changes in intracellular calcium concentration in rat primary cortical neurons. Neurotoxicology. 2007; 28(3): 622-9.

PubMed Abstract | Publisher Full Text
16. Sundaram $\mathrm{K}$, et al: : Loss of neutral ceramidase protects cells from nutrient- and energy -deprivation-induced cell death. Biochem J. 2016; 473(6): 743-55.

PubMed Abstract | Publisher Full Text | Free Full Text

17. Rajdev S, Reynolds IJ: Glutamate-induced intracellular calcium changes and neurotoxicity in cortical neurons in vitro: effect of chemical ischemia. Neuroscience. 1994; 62(3): 667-79. PubMed Abstract | Publisher Full Text

18. Simoes AP, et al.: Glutamate-induced and NMDA receptormediated neurodegeneration entails $\mathrm{P} 2 \mathrm{Y} 1$ receptor activation. Cell Death Dis. 2018; 9(3): 297.

PubMed Abstract | Publisher Full Text | Free Full Text

19. Dong WQ, et al.: The rat hippocampal slice preparation as an in vitro model of ischemia. Stroke. 1988; 19(4): 498-502. PubMed Abstract | Publisher Full Text

20. Xie $\mathrm{M}$, et al.: Oxygen and glucose deprivation-induced changes in astrocyte membrane potential and their underlying mechanisms in acute rat hippocampal slices. J Cereb Blood Flow Metab. 2008; 28(3): 456-67. PubMed Abstract | Publisher Full Text

21. Goldberg MP, Choi DW: Combined oxygen and glucose deprivation in cortical cell culture: calcium-dependent and calcium-independent mechanisms of neuronal injury.J Neurosci. 1993; 13(8): 3510-24.

PubMed Abstract | Publisher Full Text | Free Full Text

22. Katayama $Y$, et al.: Calcium-dependent glutamate release concomitant with massive potassium flux during cerebral ischemia in vivo. Brain Res. 1991; 558(1): 136-40. PubMed Abstract | Publisher Full Text

23. Rose JJ, et al.: Carbon Monoxide Poisoning: Pathogenesis, Management, and Future Directions of Therapy. Am J Respir Crit Care Med. 2017; 195(5): 596-606. PubMed Abstract | Publisher Full Text | Free Full Text

24. Sommer CJ: Ischemic stroke: experimental models and reality. Acta Neuropathol. 2017; 133(2): 245-261. PubMed Abstract | Publisher Full Text | Free Full Text

25. Richard MJ, et al.: A novel method for inducing focal ischemia in vitro. J Neurosci Methods. 2010; 190(1): 20-7. PubMed Abstract | Publisher Full Text | Free Full Text

26. Studer L, et al.: Enhanced proliferation, survival, and dopaminergic differentiation of CNS precursors in lowered oxygen. J Neurosci. 2000; 20(19): 7377-83. PubMed Abstract | Publisher Full Text | Free Full Text

27. Tiede LM, et al.: Oxygen matters: tissue culture oxygen levels affect mitochondrial function and structure as well as responses to HIV viroproteins. Cell Death Dis. 2011; 2: e246. PubMed Abstract | Publisher Full Text | Free Full Text

28. Kleman AM, et al.: Physiological glucose is critical for optimized neuronal viability and AMPK responsiveness in vitro. J Neurosci 
Methods. 2008; 167(2): 292-301.

PubMed Abstract | Publisher Full Text | Free Full Text

29. Abi-Saab WM, et al.: Striking differences in glucose and lactate levels between brain extracellular fluid and plasma in conscious human subjects: effects of hyperglycemia and hypoglycemia. J Cereb Blood Flow Metab. 2002; 22(3): 271-9.

PubMed Abstract | Publisher Full Text

30. Ravi M, et al.: 3D Cell Culture Systems: Advantages and Applications. J Cell Physiol. 2015; 230(1): 16-26. PubMed Abstract | Publisher Full Text

31. Bang S, et al.: Brain-on-a-chip: A history of development and future perspective. Biomicrofluidics. 2019; 13(5): 051301 PubMed Abstract | Publisher Full Text | Free Full Text

32. Whitesides GM, et al.: Soft lithography in biology and biochemistry. Annu Rev Biomed Eng. 2001; 3: 335-73. PubMed Abstract | Publisher Full Text

33. Stroke Therapy Academic Industry, R: Recommendations for standards regarding preclinical neuroprotective and restorative drug development. Stroke. 1999; 30(12): 2752-8. PubMed Abstract | Publisher Full Text

34. Dirnagl U, Fisher M: International, multicenter randomized preclinical trials in translational stroke research: it's time to act. J Cereb Blood Flow Metab. 2012; 32(6): 933-5. PubMed Abstract | Publisher Full Text | Free Full Text

35. Macleod MR, et al.: Good laboratory practice: preventing introduction of bias at the bench. Stroke. 2009; 40(3): e50-2. PubMed Abstract | Publisher Full Text

36. Endres $\mathrm{M}$, et al.: Improving outcome after stroke: overcoming the translational roadblock. Cerebrovasc Dis. 2008; 25(3): 268-78. PubMed Abstract | Publisher Full Text

37. Fisher $\mathrm{M}$, et al.: Update of the stroke therapy academic industry roundtable preclinical recommendations. Stroke. 2009; 40(6): 2244-50.

PubMed Abstract | Publisher Full Text | Free Full Text

38. Courtine $\mathrm{G}$, et al.: Can experiments in nonhuman primates expedite the translation of treatments for spinal cord injury in humans?. Nat Med. 2007; 13(5): 561-6.

PubMed Abstract | Publisher Full Text | Free Full Text

39. Howells DW, et al.: Different strokes for different folks: the rich diversity of animal models of focal cerebral ischemia. J Cereb Blood Flow Metab. 2010; 30(8): 1412-31. PubMed Abstract | Publisher Full Text | Free Full Text

40. Koizumi J-i, et al.: Experimental studies of ischemic brain edema. 1. A new experimental model of cerebral embolism in rats in which recirculation can be introduced in the ischemic area. Nosotchu. 1986; 8(1): p. 1-8. Publisher Full Text

41. Dirnagl U: Pathobiology of injury after stroke: the neurovascular unit and beyond. Ann N Y Acad Sci. 2012; 1268: 21-25. PubMed Abstract | Publisher Full Text

42. Longa $E Z$, et al.: Reversible middle cerebral artery occlusion without craniectomy in rats. Stroke. 1989; 20(1): 84-91. PubMed Abstract | Publisher Full Text

43. Hata $\mathrm{R}$, et al.: A reproducible model of middle cerebral artery occlusion in mice: hemodynamic, biochemical, and magnetic resonance imaging. / Cereb Blood Flow Metab. 1998; 18(4): 367-75. PubMed Abstract | Publisher Full Text

44. Engelhorn T, et al.: Decompressive craniectomy, reperfusion, or a combination for early treatment of acute "malignant" cerebral hemispheric stroke in rats? Potential mechanisms studied by MRI. Stroke. 1999; 30(7): 1456-63. PubMed Abstract | Publisher Full Text

45. Forsting $\mathrm{M}$, et al.: Decompressive craniectomy for cerebral infarction. An experimental study in rats. Stroke. 1995; 26(2): 259-64.

PubMed Abstract | Publisher Full Text

46. Garcia JH, Liu KF, Ho KL: Neuronal necrosis after middle cerebral artery occlusion in Wistar rats progresses at different time intervals in the caudoputamen and the cortex. Stroke. 1995; 26(4): 636-42; discussion 643 PubMed Abstract | Publisher Full Text

47. McColl BW, et al.: Extension of cerebral hypoperfusion and ischaemic pathology beyond MCA territory after intraluminal filament occlusion in C57BI/6J mice. Brain Res. 2004; 997(1): 15-23. PubMed Abstract | Publisher Full Text

48. Barber PA, et al:: Temperature-regulated model of focal ischemia in the mouse: a study with histopathological and behavioral outcomes. Stroke. 2004; 35(7): 1720-5. PubMed Abstract | Publisher Full Text

49. Li F, Omae T, Fisher M: Spontaneous hyperthermia and its mechanism in the intraluminal suture middle cerebral artery occlusion model of rats. Stroke. 1999; 30(11): 2464-2470; discussion 2470-1.

PubMed Abstract | Publisher Full Text

50. Percie du Sert N: The IMPROVE Guidelines (Ischaemia Models: Procedural Refinements Of in vivo Experiments). J Cereb Blood Flow Metab. 2017; 37(11): p. 3488-3517. PubMed Abstract | Publisher Full Text | Free Full Text

51. Schmid-Elsaesser $\mathrm{R}$, et al.: A critical reevaluation of the intraluminal thread model of focal cerebral ischemia: evidence of inadvertent premature reperfusion and subarachnoid hemorrhage in rats by laser-Doppler flowmetry. Stroke. 1998; 29(10): 2162-70.

PubMed Abstract | Publisher Full Text

52. Durukan A, Tatlisumak T: Acute ischemic stroke: overview of major experimental rodent models, pathophysiology, and therapy of focal cerebral ischemia. Pharmacol Biochem Behav. 2007; 87(1): 179-97.

PubMed Abstract | Publisher Full Text

53. Mohr JP, Lazar RM, Marshall RS: 24 - Middle Cerebral Artery Disease. In: Stroke (Fifth Edition). Mohr JP, et al.., Editors. 2011; Saint Louis: W.B. Saunders; p. 384-424.

54. Zanette EM, et al.: Spontaneous middle cerebral artery reperfusion in ischemic stroke. A follow-up study with transcranial Doppler. Stroke. 1995; 26(3): 430-3. PubMed Abstract | Publisher Full Text

55. Kassem-Moussa H, Graffagnino C: Nonocclusion and spontaneous recanalization rates in acute ischemic stroke: a review of cerebral angiography studies. Arch Neurol. 2002; 59(12): 1870-3.

PubMed Abstract | Publisher Full Text

56. Sutherland $B A$, et al.: The transient intraluminal filament middle cerebral artery occlusion model as a model of endovascular thrombectomy in stroke. J Cereb Blood Flow Metab. 2016; 36(2): $363-9$. PubMed Abstract | Publisher Full Text | Free Full Text

57. Goyal $\mathrm{M}$, et al.: Endovascular thrombectomy after large-vessel ischaemic stroke: a meta-analysis of individual patient data from five randomised trials. Lancet. 2016; 387(10029): 1723-31. PubMed Abstract | Publisher Full Text

58. Tamura A, et al.: Focal cerebral ischaemia in the rat: 1. Description of technique and early neuropathological consequences following middle cerebral artery occlusion. J Cereb Blood Flow Metab. 1981; 1(1): 53-60. PubMed Abstract | Publisher Full Text

59. Dirnagl U: Rodent models of stroke. In: 2 ed. Neuromethods, ed Dirnagl U 2016; New York: Springer.

60. Ren $\mathrm{M}$, et al.: Embolic middle cerebral artery occlusion model using thrombin and fibrinogen composed clots in rat. J Neurosci Methods. 2012; 211(2): 296-304.

PubMed Abstract | Publisher Full Text | Free Full Text

61. Chen $Y$, et al.: A novel mouse model of thromboembolic stroke. J Neurosci Methods. 2015; 256: 203-11. PubMed Abstract | Publisher Full Text | Free Full Text

62. Ansar S, et al.: Characterization of a new model of thromboembolic stroke in C57 black/6] mice. Trans/Stroke Res. 2014; 5(4): 526-33. PubMed Abstract | Publisher Full Text | Free Full Text

63. Zhang L, et al.: Intravenous administration of a GPIIb/IIIa receptor antagonist extends the therapeutic window of intraarterial tenecteplase-tissue plasminogen activator in a rat stroke model. Stroke. 2004; 35(12): 2890-5. PubMed Abstract | Publisher Full Text

64. Yu S, et al.: Therapeutic benefits of combined treatment with tissue plasminogen activator and 2-(4-methoxyphenyl)ethyl-2acetamido-2-deoxy-beta-d-pyranoside in an animal model of ischemic stroke. Neuroscience. 2016; 327: 44-52. PubMed Abstract | Publisher Full Text

65. Sena ES, et al.: Factors affecting the apparent efficacy and safety of tissue plasminogen activator in thrombotic occlusion models of stroke: systematic review and meta-analysis. J Cereb Blood Flow Metab. 2010; 30(12): 1905-13. PubMed Abstract | Publisher Full Text | Free Full Text

66. Zhang $F$, et al.: A stable focal cerebral ischemia injury model in adult mice: assessment using 7T MR imaging. AJNR Am J Neuroradiol. 2012; 33(5): 935-9. PubMed Abstract | Publisher Full Text

67. Stehling $F$, et al.: Acute changes of coagulation and fibrinolysis parameters after experimental thromboembolic stroke and thrombolytic therapy. Neurosci Lett. 2008; 441(1): 39-43. PubMed Abstract | Publisher Full Text

68. Zhang $Z$, et al.: A new rat model of thrombotic focal cerebral ischemia. J Cereb Blood Flow Metab. 1997; 17(2): 123-35. PubMed Abstract | Publisher Full Text 
69. Macrae IM: Preclinical stroke research--advantages and disadvantages of the most common rodent models of foca ischaemia. Br J Pharmacol. 2011; 164(4): 1062-1078. PubMed Abstract | Publisher Full Text | Free Full Text

70. Marinescu M, et al.: Clot injection technique affects thrombolytic efficacy in a rat embolic stroke model: implications for translaboratory collaborations. J Cereb Blood Flow Metab. 2014; 34(4): 677-82.

PubMed Abstract | Publisher Full Text | Free Full Text

71. Lauer $\mathrm{KK}$, et al.: Focal cerebral ischemia in rats produced by intracarotid embolization with viscous silicone. Neurol Res. 2002; 24(2): 181-90.

PubMed Abstract | Publisher Full Text

72. Purdy PD, et al.: Microfibrillar collagen model of canine cerebral infarction. Stroke. 1989; 20(10): 1361-7. PubMed Abstract | Publisher Full Text

73. Gerriets T, et al.: The macrosphere model: evaluation of a new stroke model for permanent middle cerebral artery occlusion in rats. J Neurosci Methods. 2003; 122(2): 201-11. PubMed Abstract | Publisher Full Text

74. Mayzel-Oreg O, et al.: Microsphere-induced embolic stroke: an MRI study. Magn Reson Med. 2004; 51(6): 1232-8. PubMed Abstract | Publisher Full Text

75. Horie $N$, et al.: Mouse model of focal cerebral ischemia using endothelin-1.J Neurosci Methods. 2008; 173(2): 286-90. PubMed Abstract | Publisher Full Text | Free Full Text

76. Yanagisawa $\mathrm{M}$, et al.: A novel potent vasoconstrictor peptide produced by vascular endothelial cells. Nature. 1988; 332(6163): 411-5.

PubMed Abstract | Publisher Full Text

77. Sharkey J, Ritchie IM, Kelly PA: Perivascular microapplication of endothelin-1: a new model of focal cerebral ischaemia in the rat. J Cereb Blood Flow Metab. 1993; 13(5): 865-71.

PubMed Abstract | Publisher Full Text

78. Sharkey J, Butcher SP: Characterisation of an experimental model of stroke produced by intracerebral microinjection of endothelin-1 adjacent to the rat middle cerebral artery. Neurosci Methods. 1995; 60(1-2): 125-31. PubMed Abstract | Publisher Full Text

79. Robinson MJ, et al.: Reduction of local cerebral blood flow to pathological levels by endothelin-1 applied to the middle cerebral artery in the rat. Neurosci Lett. 1990; 118(2): 269-72. PubMed Abstract | Publisher Full Text

80. Macrae IM, et al.: Endothelin-1-induced reductions in cerebral blood flow: dose dependency, time course, and neuropathological consequences. J Cereb Blood Flow Metab. 1993; 13(2): 276-84.

PubMed Abstract | Publisher Full Text

81. Biernaskie J, et al.: A serial MR study of cerebral blood flow changes and lesion development following endothelin-1induced ischemia in rats. Magn Reson Med. 2001; 46(4): 827-30. PubMed Abstract | Publisher Full Text

82. Soleman $S$, et al.: Sustained sensorimotor impairments after endothelin-1 induced focal cerebral ischemia (stroke) in aged rats. Exp Neurol. 2010; 222(1): 13-24. PubMed Abstract | Publisher Full Text | Free Full Text

83. Gilmour $\mathrm{G}$, et al.: The effects of intracortical endothelin-1 injections on skilled forelimb use: implications for modelling recovery of function after stroke. Behav Brain Res. 2004; 150(1-2): 171-83.

PubMed Abstract | Publisher Full Text

84. Watson $\mathrm{BD}$, et al.: Induction of reproducible brain infarction by photochemically initiated thrombosis. Ann Neurol. 1985; 17(5): 497-504.

PubMed Abstract | Publisher Full Text

85. Kim GW, Sugawara T, Chan PH: Involvement of oxidative stress and caspase- 3 in cortical infarction after photothrombotic ischemia in mice. J Cereb Blood Flow Metab. 2000; 20(12): 1690-701. PubMed Abstract | Publisher Full Text

86. Uzdensky AB: Photothrombotic Stroke as a Model of Ischemic Stroke. Trans/ Stroke Res. 2018; 9(5): 437-451.

PubMed Abstract | Publisher Full Text

87. Sutherland BA, et al.: Neuroprotection for ischaemic stroke: translation from the bench to the bedside. Int J Stroke. 2012; 7(5): 407-18.

PubMed Abstract | Publisher Full Text

88. Dirnagl U: Bench to bedside: the quest for quality in experimental stroke research. J Cereb Blood Flow Metab. 2006; 26(12): 1465-78.

PubMed Abstract | Publisher Full Text

89. Dirnagl U, Macleod MR: Stroke research at a road block: the streets from adversity should be paved with meta-analysis and good laboratory practice. BrJ Pharmacol. 2009; 157(7): 1154-6.

PubMed Abstract | Publisher Full Text | Free Full Text

90. Bath PM, et al.: Effects of NXY-059 in experimental stroke: an individual animal meta-analysis. Br J Pharmacol. 2009; 157(7): 1157-71.

PubMed Abstract | Publisher Full Text | Free Full Text

91. Crossley NA, et al.: Empirical evidence of bias in the design of experimental stroke studies: a metaepidemiologic approach. Stroke. 2008; 39(3): 929-34.

PubMed Abstract | Publisher Full Text

92. Macleod MR, et al.: Evidence for the efficacy of NXY-059 in experimental focal cerebral ischaemia is confounded by study quality. Stroke. 2008; 39(10): 2824-9.

PubMed Abstract | Publisher Full Text

93. Ingberg $\mathrm{E}$, et al.: Method parameters' impact on mortality and variability in mouse stroke experiments: a meta-analysis. $S c i$ Rep. 2016; 6: 21086

PubMed Abstract | Publisher Full Text | Free Full Text

94. Carmichael ST: Rodent models of focal stroke: size, mechanism, and purpose. NeuroRx. 2005; 2(3): 396-409. PubMed Abstract | Publisher Full Text | Free Full Text

95. Dirnagl UM.o.t.M.-S.O.P. Group: Standard operating procedures (SOP) in experimental stroke research: SOP for middle cerebral artery occlusion in the mouse. Nature Precedings. 2012.

Publisher Full Text

96. Kitagawa K, et al.: Cerebral ischemia after bilateral carotid artery occlusion and intraluminal suture occlusion in mice: evaluation of the patency of the posterior communicating artery. J Cereb Blood Flow Metab. 1998; 18(5): 570-9.

PubMed Abstract | Publisher Full Text

97. Barone FC, et al.: Mouse strain differences in susceptibility to cerebral ischemia are related to cerebral vascular anatomy. J Cereb Blood Flow Metab. 1993; 13(4): 683-92.

PubMed Abstract | Publisher Full Text

98. Hara $\mathrm{H}$, et al.: Reduced brain edema and infarction volume in mice lacking the neuronal isoform of nitric oxide synthase after transient MCA occlusion. J Cereb Blood Flow Metab. 1996; 16(4): 605-11.

PubMed Abstract | Publisher Full Text

99. Fujii $\mathrm{M}$, et al.: Strain-related differences in susceptibility to transient forebrain ischemia in SV-129 and C57black/6 mice. Stroke. 1997; 28(9): 1805-10; discussion 1811. PubMed Abstract | Publisher Full Text

100. Trotman-Lucas $M$, et al.: Improved reperfusion following alternative surgical approach for experimental stroke in mice. F1000Res. 2020; 9: p. 188

PubMed Abstract | Publisher Full Text | Free Full Text

101. Trotman-Lucas $M$, et al.: An alternative surgical approach reduces variability following filament induction of experimental stroke in mice. Dis Model Mech. 2017; 10(7): 931-938.

PubMed Abstract | Publisher Full Text | Free Full Text

102. Dittmar $\mathrm{M}$, et al.: External carotid artery territory ischemia impairs outcome in the endovascular filament model of middle cerebral artery occlusion in rats. Stroke. 2003; 34(9): 2252-7.

PubMed Abstract | Publisher Full Text

103. Trueman RC, et al.: A Critical Re-Examination of the Intraluminal Filament MCAO Model: Impact of External Carotid Artery Transection. Trans/ Stroke Res. 2011; 2(4): 651-61. PubMed Abstract | Publisher Full Text

104. Liu S, et al.: Rodent Stroke Model Guidelines for Preclinical Stroke Trials (1st Edition). J Exp Stroke Trans/ Med. 2009; 2(2): 2-27. PubMed Abstract | Publisher Full Text | Free Full Text

105. Trotman-Lucas M, et al.: Middle Cerebral Artery Occlusion Allowing Reperfusion via Common Carotid Artery Repair in Mice. J Vis Exp. 2019; 143 PubMed Abstract | Publisher Full Text

106. Russell WMS, Burch RL: The principles of humane experimental technique. 1959; London: London: Methuen. 238.

107. Prescott MJ, Lidster K: Improving quality of science through better animal welfare: the NC3Rs strategy. Lab Anim (NY). 2017 46(4): 152-156.

PubMed Abstract | Publisher Full Text

108. Guzman R, Janowski M, Walczak P: Intra-Arterial Delivery of Cell Therapies for Stroke. Stroke. 2018; 49(5): p. 1075-1082. PubMed Abstract | Publisher Full Text | Free Full Text

109. Argibay $B$, et al.: Intraarterial route increases the risk of cerebral lesions after mesenchymal cell administration in animal model of ischemia. Sci Rep. 2017; 
7: 40758.

PubMed Abstract | Publisher Full Text | Free Full Text

110. Dittmar MS, et al.: The role of ECA transection in the development of masticatory lesions in the MCAO filament model. Exp Neurol. 2005; 195(2): 372-8.

PubMed Abstract | Publisher Full Text

111. Fehm NP, et al.: Closing microvascular lesions with

fibrin sealant-attached muscle pads. Microsurgery. 2005; 25(7):

570-4.

PubMed Abstract | Publisher Full Text
112. Ge J, et al.: The size of mesenchymal stem cells is a significant cause of vascular obstructions and stroke. Stem Cell Rev Rep. 2014; 10(2): 295-303.

PubMed Abstract | Publisher Full Text

113. Corbett $D$, et al.: Enhancing the alignment of the preclinical and clinical stroke recovery research pipeline: Consensus-based core recommendations from the Stroke Recovery and

Rehabilitation Roundtable translational working group. Int J

Stroke. 2017; 12(5): 462-471.

PubMed Abstract | Publisher Full Text 


\section{Open Peer Review}

\section{Current Peer Review Status:}

\section{Version 1}

Reviewer Report 12 May 2021

https://doi.org/10.5256/f1000research.54949.r82456

C 2021 Chen R. This is an open access peer review report distributed under the terms of the Creative Commons Attribution License, which permits unrestricted use, distribution, and reproduction in any medium, provided the original work is properly cited.

\section{Ruoli Chen}

School of Pharmacy and Bioengineering, Keele University, Staffordshire, UK

This is an excellent review article summarising experimental models of ischaemic stroke. It not only provides introduction with critical comments on both in vitro and in vivo preclinical models of ischaemic stroke, but also puts forward some proposals to refine iMCAO, the most commonly used in vivo model of ischameic stroke. iMACO produces lesion volumes with large standard deviation, thus has low statistical power. The authors have previously reported an alterative surgical approach to iMCAO, e.g, avoidance ECA ligation, providing analgesia. In this review article, the authors highlight iMCAO CCA repair method to further reduce lesion volume variability.

Is the topic of the review discussed comprehensively in the context of the current literature?

Yes

Are all factual statements correct and adequately supported by citations?

Yes

Is the review written in accessible language?

Yes

Are the conclusions drawn appropriate in the context of the current research literature? Yes

Competing Interests: No competing interests were disclosed.

Reviewer Expertise: neuroprotection, blood brain barrier, hypoxia

I confirm that I have read this submission and believe that I have an appropriate level of expertise to confirm that it is of an acceptable scientific standard. 
Reviewer Report 26 April 2021

https://doi.org/10.5256/f1000research.54949.r82453

(C) 2021 Work L. This is an open access peer review report distributed under the terms of the Creative Commons Attribution License, which permits unrestricted use, distribution, and reproduction in any medium, provided the original work is properly cited.

\section{Lorraine M. Work}

Institute of Cardiovascular \& Medical Sciences, University of Glasgow, Glasgow, UK

The review by Trotman-Lucas \& Gibson is comprehensive and covers the various experimental models of ischaemic stroke available having also described the in vitro models which may be used to support in vivo studies. The detail is appropriate for a review, it is well written and supported through citation of the primary research material.

One suggested addition to improve the ease of access to the information described and discussed would be the inclusion of a summary table highlighting key considerations of each model (e.g. whether reperfusion can be achieved, ease of surgical technique required, limitations).

Is the topic of the review discussed comprehensively in the context of the current literature?

Yes

Are all factual statements correct and adequately supported by citations? Yes

Is the review written in accessible language?

Yes

Are the conclusions drawn appropriate in the context of the current research literature? Yes

Competing Interests: No competing interests were disclosed.

Reviewer Expertise: Preclinical models of experimental stroke

I confirm that I have read this submission and believe that I have an appropriate level of expertise to confirm that it is of an acceptable scientific standard.

Author Response 20 May 2021

claire gibson

Thank you for these thoughtful comments from the reviewer. We agree that a table would be informative and have now included this in our revision. 
Competing Interests: No competing interests were disclosed.

The benefits of publishing with F1000Research:

- Your article is published within days, with no editorial bias

- You can publish traditional articles, null/negative results, case reports, data notes and more

- The peer review process is transparent and collaborative

- Your article is indexed in PubMed after passing peer review

- Dedicated customer support at every stage

For pre-submission enquiries, contact research@f1000.com 